\title{
EDUCAÇÃO FORMAL e TREINAMENTO: confundir para doutrinar e dominar
}

\author{
Valdo José Cavallet ${ }^{1}$
}

Nos dois últimos séculos, com inúmeras inovações tecnológicas e estruturais, com o avanço significativo da Ciência, com as rupturas nas tradições, nas formas de expressão e das relações humanas, pelo aumento da velocidade e a diminuição das distâncias de espaço e tempo, com a ênfase dada na personalização, na competitividade e na simulação do cotidiano pelas imagens intensificadas dos meios de comunicação de massa, as instituições sociais encarregadas da educação passaram a viver um dualismo: a formação integral, do homem para a vida, e a formação técnica e especializada, do homem para o trabalho.

Estes aspectos podem ser dicotômicos ou complementares. A disputa pela hegemonia da concepção econômica de educação, que seria determinada pelo mercado, sobre a concepção social e humana, voltada ao desenvolvimento integral do homem, representaria o aspecto dicotômico na medida que tem uma expectativa de não mudar o homem do ponto de vista de sua construção, mas adaptá-lo ao mundo do trabalho que está em mudança. A complementaridade dos aspectos ocorreria ao se estabelecer conscientemente o desenvolvimento de ambas as formas, com métodos apropriados.

A sociedade é complexa e são caracterizadas circunstâncias de crise pelos mais diversos segmentos sociais. $\mathrm{O}$ modelo de desenvolvimento em vigor tem se mostrado ineficaz para superar os grandes desafios da atualidade. Portanto, o que ocorre é uma crise de paradigma. A educação é apontada como solução para a crise. Mais do que nunca, a escolarização tem sido colo-

* Professor da UFPR. Mestre em Agronomia pela UFPR. Doutor em Educação pela USP. Estudos Complementares em Desenvolvimento e Formação Profissional pela Universidade de Pisa/Itália. (cavallet@agrarias.ufpr.br) 
cada em destaque por representantes dos mais diversos segmentos sociais. Frente aos desafios da atualidade, até o sistema financeiro internacional, de forma explicita e inédita, passou a defender a intensificação dos processos de escolarização. (TOMMASI; WARDE; HADDAD, 1998)

Os departamentos de educação de Instituições Financeiras, como 0 Banco Mundial, passaram a ocupar um espaço estratégico na formulação e implementação de novos modelos escolares. Em suas políticas a escola transforma-se numa linha de montagem, capaz de resolver todos os problemas e contradições do modelo de desenvolvimento adotado. Como se toda a teoria educacional acumulada na história tivesse sido um grande engano dos educadores, executivos como o chefe do departamento de educação do Banco Mundial (CASTRO, 1999), num diletantismo credenciado pela grande imprensa, em função dos postos que ocupam, afirmam taxativamente que nem sequer mais o modelo pedagógico interessa: basta ser aluno normal que aprenderá tudo o que interessa, independente da linha pedagógica. Reduz-se a educação escolar a treinamento para competir por oportunidades de trabalho. A formação integral, social e humana, é relegada a plano secundário ou inexistente.

Com a doutrina imposta pelas instituições financeiras, caminha-se inversamente à construção de uma política educacional de superação, as políticas públicas desaparecem, dando lugar aos negócios empresariais, caracterizados pela curta duração, alta flexibilidade e inexistência de unidade - treinamentos rápidos e amplamente diversificados de cunho econômico-produtivo, que visam preparar a pessoa para ser altamente competitiva no processo de trabalho, e paralelamente, pretendem vender o produto educação, que transformou-se numa grande oportunidade. Embora transforme a pessoa competitivamente, esta fórmula também é alienante. A educação para o trabalho como fim, prende o sujeito dentro do processo de trabalho. Além das categorias mão-de-obra e mente-de-obra, agrega-se às demais categorias alienantes, uma nova, a mente-de-consumo. (DE MASI, 1999)

Na sociedade agrícola os setores dominantes reduziam os dominados a mão-de-obra, que analfabetos e pelo trabalho braçal, atendiam as demandas da elite. Na sociedade industrial, com o desenvolvimento tecnológico, somouse à mão-de-obra, a mente-de-obra, que pelo treinamento escolar contribuíram para modernizar o sistema produtivo e as formas de dominação. Agora, na sociedade pós-industrial acrescenta-se à mão-de-obra e à mente-de-obra, a mente-de-consumo. A formação do modelo dominante, além de preparar para o processo produtivo, passa a ser uma mercadoria de massa, de demanda infinita, e, propiciadora de grandes acúmulos financeiros aos seus idealizadores e provedores.

O utilitarismo do modelo de educação, proposto pelos setores domi- 
nantes, sobrepõe-se ao espaço educacional, na sua luta histórica de construção do homem e transformação da sociedade. Objetiva o atendimento das necessidades imediatas, transformando o processo de educação em produto final de venda, que atende ao mundo do trabalho, negligenciando os excluídos e as necessidades mais particularizadas. Confunde-se intencionalmente, chamando tudo de educação, retirando o espaço de construção da consciência. A concepção está separada da execução, sendo elaborada pelos responsáveis pelo modelo de desenvolvimento econômico para atender necessidades imediatas.

Não se invalida a forma de treinamentos rápidos e diversificados e a formação para o trabalho, principalmente quando entendidos como meio num contexto onde se preserva o espaço para a formação mais abrangente.

Necessário porém, pensar qual o modelo pedagógico que se pretende: o que contribui para formar um ser consciente, capaz de se entender e se ver no mundo, que possa construir a vida e o mundo como um todo ou o que pensa isto como meio de desenvolver o sentido do trabalho. Mas a educação, embora confundida pelo senso dominante com os treinamentos rápidos de preparo, que objetivam a manutenção do modelo de desenvolvimento econômico vigente, tem diferentes papéis. Não se nega a formação como meio, mas esta deve merecer o seu devido espaço, integrada à formação que possibilite a construção de um projeto de vida, de trabalhar com a realidade acompanhando suas evoluções, com características de especialização e generalização e o desenvolvimento da capacidade crítica, que tem como princípio educativo a pesquisa. (DUARTE, 1999)

O homem deve ter uma formação para a vida, a ele deve ser permitida a condição de construção de um projeto de vida, de buscar uma profissionalidade ${ }^{2}$; portanto, uma capacidade de se inserir, de compreender 0 mundo e transformá-lo, pela capacitação para conceber novos processos e paradigmas, com a visão de desenvolvimento social; amparado por políticas públicas, com inserção nos movimentos sociais; baseado em toda a teoria educacional, com a visão crítica dos educadores; feitos em instituições educacionais, num processo integrado na sociedade, com visão interdisciplinar e cooperativa, compatível com cada acúmulo realizado; que tenha o princípio educativo da pesquisa, que crie consciência e propicie uma integração entre das pessoas que estão excluídas. Os sindicatos, juntamente com outras representações sociais, podem desenvolver, para dar conta, tanto de inserir os trabalhadores economicamente a curto prazo, como possibilitar projetos de vida e transformações sociais, um projeto pedagógico, com linhas norteadoras semelhantes às apontadas neste parágrafo. Um projeto que pense além, e inclua questões como saúde e qualidade de vida, resgate e respeito às identificações culturais e necessidades pessoais. 


\begin{tabular}{|c|c|c|}
\hline Aspectos/Modelos escolares & Formação Técnica & Educação ProfissionaleHumana \\
\hline O QUE modelo possibilita? & Ocupação $^{3}$ & Profissão ${ }^{4}$ \\
\hline O QUßuscam os participantes? & Necessidades imediatas & Projeto de vida \\
\hline \multicolumn{3}{|l|}{ POR QUE? } \\
\hline Característica.. & Competitividade & Cooperação \\
\hline \multirow{3}{*}{ 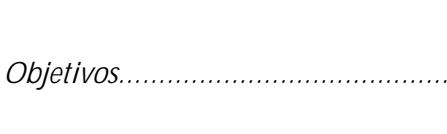 } & Empregabilidade & Profissionalidade \\
\hline & Disputar os espaços existentes & Conceber novos processos \\
\hline & Lucro & Desenvolvimento social \\
\hline Tipo de a tividade & Negócio Empresarial & Política Pública \\
\hline $\begin{array}{l}\text { C O MO : } \\
\text { • Idealizadores............................... }\end{array}$ & $\begin{array}{l}\text { Instituições Financeiras } \\
\text { Setores Empresariais } \\
\text { (Economistas) }\end{array}$ & $\begin{array}{l}\text { Instituições Educacionais } \\
\text { Movimentos Sociais } \\
\text { (Educadores) }\end{array}$ \\
\hline \multirow{2}{*}{ • Referencial teórico....................... } & Teoria Econômica & Teoria Educacional \\
\hline & Processo separados & Processo integrado \\
\hline \multirow{2}{*}{$\begin{array}{l}\text { • Estrutura Curricular................... } \\
\text { • Tempo Curricular......................... }\end{array}$} & $\begin{array}{l}\text { Módulos Específicos e } \\
\text { Intensivos em Unidades } \\
\text { especializadas }\end{array}$ & $\begin{array}{l}\text { Formação integral e contínua } \\
\text { em Centros interdisciplinares }\end{array}$ \\
\hline & Curta duração & $\begin{array}{l}\text { Compatível c/maturidade } \\
\text { intelectual }\end{array}$ \\
\hline • Abordagem Pedagógica.............. & $\begin{array}{l}\text { Transmissão/Reprodução } \\
\text { Treinamento }\end{array}$ & $\begin{array}{l}\text { Ensino c/ Pesquisa } \\
\text { problematizada Educação } \\
\text { reflexiva }\end{array}$ \\
\hline • Resultante Pedagógica................ & Condicionamento & Conscientização \\
\hline Conseqüências & Exclusão & Integração \\
\hline
\end{tabular}

O esquema abaixo, ilustra as diferenças entre um modelo de formação técnica e um modelo de educação profissional e humana, e, sem a pretensão de esgotar a discussão sobre o tema, pode nortear a construção de um novo modelo pedagógico de formação.

Na construção de um modelo pedagógico é prioritário que se tenha clareza sobre o ideal e o perfil buscado e sobre quais compromissos norteiam esta busca. No momento seguinte, é importante a seleção de princípios educativos que possibilitem a concretização deste perfil (que não seja algo utópico) e na seqüência, a elaboração de uma proposta curricular exeqüível e que propicie atingir os objetivos pretendidos.

O perfil constitui-se da convergência de múltiplas opiniões e posicionamentos das partes envolvidas. Apesar disto ousamos sugerir uma linha macro, que seria a de um sujeito capaz de responder por atividades imediatas, criar novos processos e a o mesmo tempo criar projetos de vida, bus- 
cando a profissionalidade. O que possibilita a construção do perfil é o modelo pedagógico. Para atender a um perfil é preciso definir um princípio educativo. O principio educativo tem que estar concretizado numa atividade pedagógica, portanto, uma atividade curricular.

A concepção de um modelo deve ser uma etapa do processo educativo, concebida integradamente pela comunidade curricular: educadores e educandos. (JORGE, 1993)

A separação entre a concepção e a execução da formação profissional, onde o contato entre os agentes educacionais para o planejamento curricular é minimizado, dificulta o desenvolvimento de habilidades pedagógicas direcionadas a questionar as contradições da formação dos estudantes. Os professores, preocupados com a execução de conteúdos especializados, permanecem distanciados do objetivo principal da educação: a formação harmoniosa e integral de um profissional e cidadão. A formação proveniente de um currículo concebido numa esfera e executado em outra, através de docentes especializados em diferentes áreas do conhecimento, além de proporcionar um caráter sincrético ${ }^{5}$ ao projeto pedagógico, facilita sobremaneira a produção e reprodução do conhecimento acrítico. (CAVALLET, 1999)

Frente às necessidades de transformações sociais e diante da limitação do modelo de formação imposto pelos setores dominantes, defende-se alterações que sejam capazes de propiciar ao conjunto da população o discernimento e a aptidão para que venham contribuir de forma decisiva para 0 futuro da sociedade. Trabalhando-se dialeticamente com o conhecimento humano e com suas inerentes contradições, há espaço para a construção de processos curriculares que possibilitem a formação de profissionais socialmente mais compromissados.

Paulo FREIRE (1978, 1986, 1998) educador brasileiro reconhecido mundialmente, defendeu a educação, como dinamizadora do processo de mudança, através de um método ativo e participativo, firmando bases da aprendizagem:

- Capacidade de auto-reflexão como desenvolvimento da consciência crítica, que reorganiza as experiências vividas, transformando a realidade;

- A aprendizagem modifica o homem que, ao mesmo tempo em que se renova, mantém a própria identidade. Portanto, uma aprendizagem libertadora de conquista e aumento da autonomia;

- A busca permanente como sujeito, e não objeto da educação; com a consciência da característica humana de ser inacabado;

- A noção do tempo, que diferencia homens de animais, e caracteriza o homem como ser histórico, capaz de construir o futuro com base no passado.

Essas bases possibilitam a teoria educacional afirmar que:

- a criatividade e inovação só se desenvolvem no exercício da liber- 
dade, definida como capacidade de escolher entre as alternativas com a clara compreensão de suas conseqüências;

- a práxis criadora somente ocorre com a incorporação do aprendizado refletido, que flui das trocas entre mestre e aprendiz, participativamente, na construção da realidade, pelas decisões do presente.

É importante que seja desenvolvida uma forma de internalizar a ampliação constante de conhecimentos, culturalmente amplos e suficientemente específicos, para que sejam aplicáveis em alternativas e soluções significativas na viabilização dos objetivos da educação. É necessária a consciência das ligações entre os atos praticados e os componentes do meio onde se inserem.

Diferente de treinar o ser humano para uma ocupação no mercado de trabalho, a ação educativa deve formar um profissional para contribuir, através da geração, intermediação e inter-relação do conhecimento, de forma decisiva na busca de um desenvolvimento baseado na eficiência, eqüidade e sustentabilidade. Para esse novo profissional, o trabalho deve ser um ato político-social consciente.

A profissionalidade resultará de uma aprendizagem permanente, que será desencadeada por uma formação inicial, integralizada com consistência pedagógica rigorosamente adequadas ao grau de complexidade científica e responsabilidade de cada uma das atividades desenvolvidas na sociedade contemporânea.

Por outro lado, as transformações sociais, pressupõem a superação do utilitarismo e do reducionismo promovido pelos setores dominantes sobre as políticas educacionais.

\section{Notas bibliográficas}

1. Profissionalidade é um neologismo utilizado, como indicativo da capacidade do profissional em implementar alternativas eficazes diante da crise e dos problemas da atualidade tanto imediatas, como de projetos de vida.(CAVALET, 1999)

2. Neste texto, a ocupação é entendida como a atividade humana que se preocupa em atender às demandas normais da sociedade, através da repetição de soluções já conhecidas. Diferencia-se de profissão, na medida em que essa última, ocupa-se, além de atender demandas normais, através de soluções já consagradas, em produzir análises, consolidar novos marcos teóricos e em criar e desenvolver novos processos.

3. Uma profissão é constituída pelos seguintes elementos básicos que a caracterizam: conceito, ideal, objetivos sociais, formação acadêmica, conteúdos específicos, regulamentação profissional, autonomia, entidades representativas, código de ética e reconhecimento social. (CAVALET, 1999)

4. Visão de conjunto confusa, de uma totalidade complexa, decorrente da junção de doutrinas e concepções heterogêneas e não articuladas entre si. 


\section{Referências Bibliográficas}

CASTRO, Claudio Moura. Pais não sabem o que procurar. Revista Época, São Paulo, n. 73, p.88, 11 out. 1999.

CAVALLET, Valdo José. A formação do engenheiro agrônomo em questão: a expectativa de um profissiomal que atenda as demandas sociais do século XXI. São Paulo, 1999. Tese (Doutorado em Educação) - Faculdade de Educação. Universidade de São Paulo.

DE MASI, Domenico. Desenvolvimento sem trabalho. 2. ed. São Paulo: Esfera, 1999.

DUARTE, Newton. Educação escolar, teoria do cotidiano e a escola de Vigotski. 2. ed. Campinas: Autores Associados, 1999.

FREIRE, Paulo. Ação cultural para a liberdade. 3. ed. Rio de Janeiro: Paz e Terra, 1978.

FREIRE, Paulo. Educação como prática da liberdade. 17. ed. Rio de Janeiro: Paz e Terra, 1986.

FREIRE, Paulo. Pedagogia da esperança: um reencontro com a pedagogia do oprimido. 5. ed. Rio de Janeiro: Paz e Terra, 1998.

JORGE, Leila. Inovação curricular: além da mudança dos conteúdos. Piracicaba: Unimep, 1993.

TOMMASI, Livia; WARDE, Miriam Jorge; HADDAD, Sérgio (Orgs.). O Banco Mundial e as políticas educacionais. 2. ed. São Paulo: Cortez, 1998. 